\title{
Visualizing under pressure: parametric modeling of urban morphology as an agile and transparent tool for participatory planning in Brazil
}

XXIV International Conference

of the Iberoamerican Society

of Digital Graphics

Medellin | Colombia

\author{
Hélio Takashi Maciel de Farias \\ UFRN | Brazil | htmfarias@gmail.com \\ Amíria Bezerra Brasil \\ UFRN | Brazil | htmfarias@gmail.com \\ Fabrício Lira Barbosa \\ UFRN | Brazil | htmfarias@gmail.com
}

\begin{abstract}
Urban morphology in Brazilian cities is deeply related to building code parameters, such as maximum floor-to-area-ratio and building height. Planning regulations for city of Natal/RN are currently being revised, under intense industry pressure towards increasing building density in the coastal areas, despite social and environmental concerns. Prospective visualizations of multiple parametrically modeled scenarios were developed as aids in explaining the impacts of such regulation changes in a participatory planning context. Despite lacking extensive resources or data to support their development, the visualizations and the associated density information were sufficiently communicative as to be incorporated into the planning discussion.
\end{abstract}

Keywords: Participatory planning; Parametric urban modeling; Urban morphology visualization

\section{INTRODUCTION}

Brazilian urban planning law defines each municipality's Director Plan as the main means of setting urban policy as it relates to land use, building density, infrastructure use and the preservation of the territory's environmental, socia and historical values. The instruments contained in the Plan directly affect urban morphology through the definition of parameters such as maximum floor-to-area-ratio, parcel occupation and building height that direct densification and shape the built landscape (De Castro et al, 2018).

Natal, capital city in the Rio Grande do Norte state, is undergoing a plan revision which, as a result of intense pressure by the local building industry, is set to alter how these parameters are approached, resulting in a large increase in potential urban density. The changes incorporated into the current propositions are based on data tables and density modeling that are not generally publicized, resulting in a lack of clarity and social control over the involved variables. Equally concerning are the obstacles posed by the specialized information required to knowledgeably intervene in the planning process - which is required by law to be a participatory construction but is often out of reach for citizens that have not received specialist training. The situation has been exacerbated by the COVID-19 pandemic and the associated social distancing measures, as the process continues despite a context of unequal access to digital communication technologies. This study explores the use of parametric visualizations as a means of educating and generating engagement in a context of participatory planning, focusing on the strategies used to model and publicize alternative scenarios, and reports on the impact these visualizations have had on the narrative and discussion surrounding a highly contested decision-making process.

\section{VISUALIZATION AS A TOOL FOR PARTICIPATION}

Urban planning laws translate an ample set of concerns, such as urban density control, infrastructure management, mobility, vitality, sustainable development and the right to the city, into applicable instruments that interact in a complex system of physical and social relationships: the urban environment. Brazilian planning law, especially since the establishment of the 2001 "Estatuto da Cidade" (Brasil, 2001) federal law, has represented these concepts, among others, as objectives embedded in each municipality's Director Plan, documents that consist of large volumes of legal text, accompanied by numeric tables and maps representing various scales of the territory. The same law defines Participatory Planning as an indispensable part of the planning process. Given that, it is up to each municipality to tackle the challenges of properly informing and integrating its citizens into said process.

Urban visualization has been cited as important strategy to explore alternatives, explain concepts and propositions, as well as educate, engage and empower citizens (Batty et al. 2004; Pettit \& Industries, 2006). Whereas legal text and two-dimensional maps may obscure some of the tangible effects of planning decisions, "Visualization of the potential of urban sites could assist in turning passive and bitter residents into engaged urban citizens" (Kallus, 2016, p. 632 ). As such, the tools used for visualization, from lowtechnology solutions such as free sketching, to digital collage, augmented reality and virtual reality and others, have been explored by various studies focused on diverse participatory scenarios, with the most usual findings pointing to the use of visual information as a means of overcoming communication barriers, reducing the risk for confusion and increasing the citizens' ability to contribute to the decision-making process. (Al-Kodmany, 2002, 
Remaking Cities Institute, 2019). These visualizations have proved themselves a powerful tool in eliciting reactions from agents involved in the planning process, and as such require special care as it relates to the content and form of presentation (Lovett at al, 2015), and well as the transparency of the process, so as to maintain credibility in the final product (Sheppard, 2001).

\section{THE NATAL DIRECTOR PLAN REVISION}

The current Director Plan (Natal, 2007) for the city of Natal/RN (total estimated population 884.112, as of the year 2019) addresses planning by defining three main zones in the city's territory: basic density, densification, and environment protection; augmented by a number of special areas, namely: touristic interest, social interest, historical interest, and urban operations. Each of these areas is mainly characterized by having specific parameters for maximum floor-to-area ratio, plot occupancy, ground impermeability and building height, and any special case restrictions deemed necessary for environmental, social, or other reasons. As required by law, this Plan has been scheduled for a revision process which began in 2017 and has since been the object of contention due to limited transparency on the revision's objectives and underlying data, and a perceived failure to effectively allow citizen participation.

As a response to these problems, a group of professors and students from the Federal University of Rio Grande do Norte organized the "Right to the City Forum" (Fórum Direito à Cidade - FDC) outreach project, aiming to bring together professionals from diverse fields related to Urban Planning and the citizen community. As the revision process resumed in 2019 after a hiatus, the FDC promoted citizen education and engagement projects and answered community requests for clarification on specific issues related to the Plan's concepts or to expected changes directly affecting their own neighborhoods. The revision phase scheduled to take place during August 2019 consisted of nine official workshops and content expositions dealing with several aspects of planning, imposing a tight timetable during which citizens of various interests groups would need to understand planning

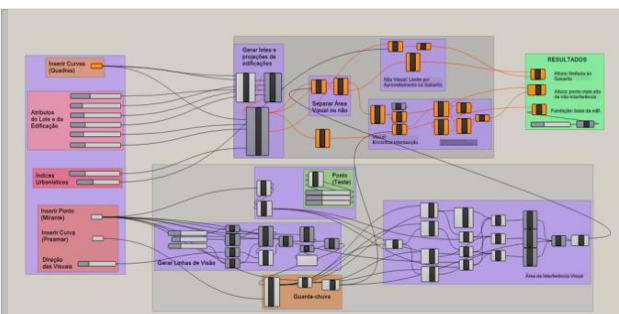

concepts as they related to the city and its plan, and define priority issues for planning consideration.

Even though the FDC considered this revision methodology to be deeply flawed in its methods and scheduling, all possible efforts were made to include viable information that might aid in citizen participation. At this point, an agile solution for visualization was needed in order to demonstrate possible future scenarios resulting from planning law changes.

\section{BUILDING THE VISUALIZATIONS}

The visualization efforts had to answer the questions of what should be included, as well as when and how the presentation should take place. Also, "time, budget, staff expertise, computing facilities and data are also important considerations" (Lovett et al., 2015, p. 88). Given the planning process tended to deal with building parameter changes over large urban areas, and given the need to emphasize the effects these changes would have on the natural and built landscape, the main tool used to produce the visualizations was three-dimensional computational modeling - chosen as a means to demonstrate the effects that changes in the plan could have on building morphology.

The data available for this project was limited to CAD data (terrain and building projections), and aggregate population data - there is no publicly available, comprehensive GIS data for the city. Also considering the short available timeframe and the limited human and computational resources available, the visualization team chose to base this task on a previously tested method of parametric modeling using the Grasshopper plugin embedded into the Rhinoceros 3D modeling software (Figure 1).

Other aspects also had to be defined when planning the visualization work. Even though it would be possible (if more difficult given the proposed schedule) to represent the modeled morphology with some degree of realism (for instance, using texture mapping and procedural façade modeling), a low-realism visual style, based on solid forms and little geometric complexity, was deemed preferable, in

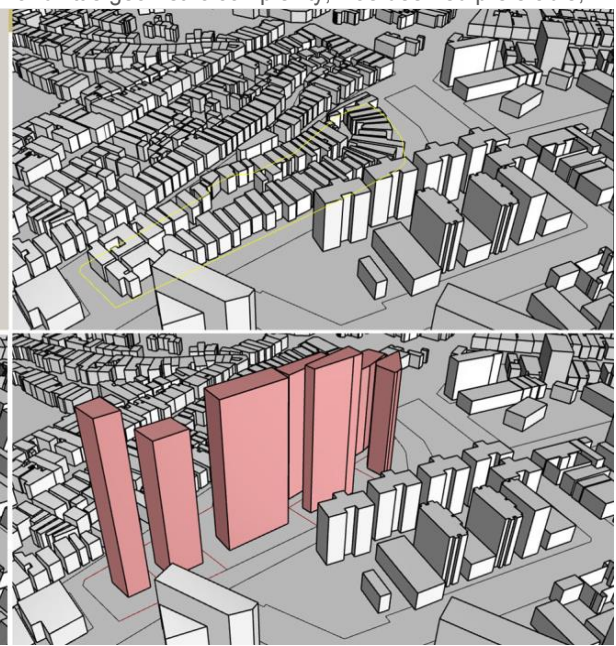

Figure 1: Visualizing urban morphology in context: Grasshopper definition (top left); existing city block (top right); reconfiguration with $F A R=1.2$ (bottom left); reconfiguration with FAR=3.5 (bottom right) 

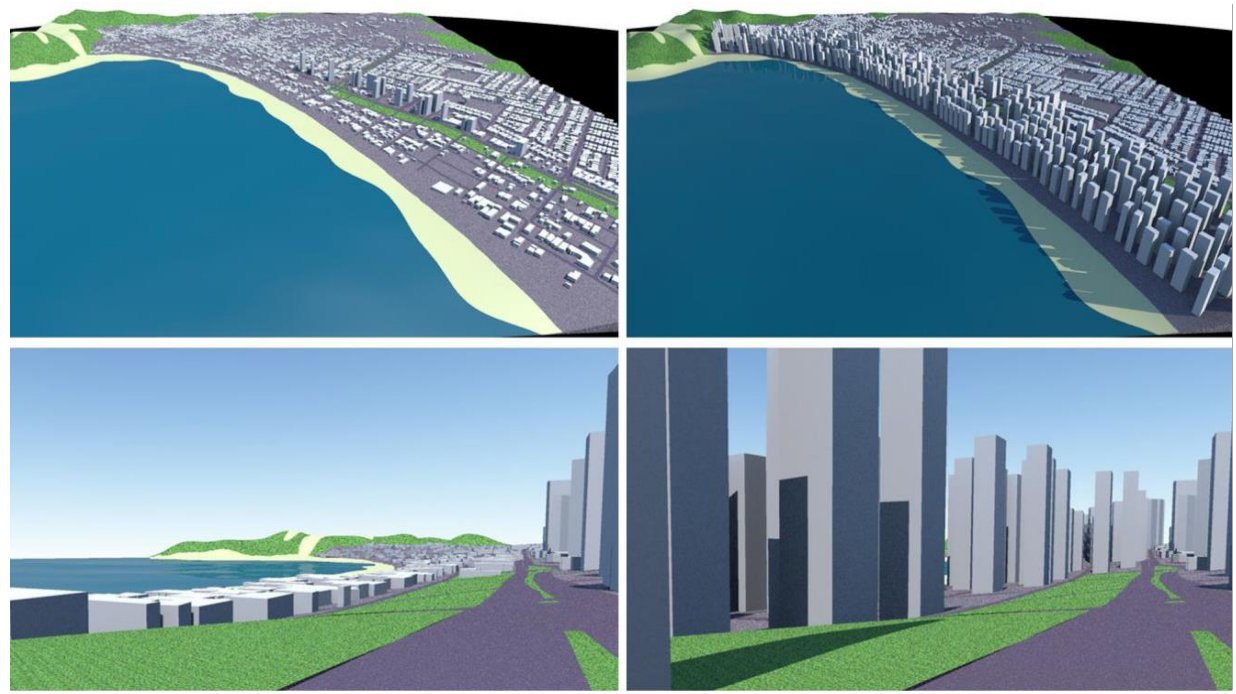

Figure 2: "Ponta Negra" visualizations: Bird's eye view, current (top left); Bird's eye view, FAR 3.5 (top-right); Street-level, current (bottom-left); Street-level, FAR 3.5 (bottom-right)

order to avoid the twofold risks of distracting the viewers from the intended communication or to mislead by emulating "truthfulness" in a what should be a merely conceptual representation (Al-Kodmany, 2002), while still containing the most important information needed for a specific purpose (Lange, 2001, p. 165).

Regarding the desired point-of-view, two main sets of images were generated for each scenario: bird's eye views, which help understand the context and compare the effects of parameter changes over a large area, and street-level views, which facilitate orientation and display the built environment's occlusion effects on the natural landscape (Lovett el at., 2015).

While a higher level of immersion and interactivity in the visualizations might be desirable when planning in a participatory context, the use of such technologies as Virtual Reality, ambient sound and controllable avatars require a great amount of resources, participant and staff training (Hoch et al., 2015; Lindquist, Lange, \& Kang, 2016; Remaking Cities Institute, 2019), which were unavailable during the plan revision process. The use of still images aided by textual information, on the other hand, provide a greater ease of presentation and distribution over various platforms. This would allow the visualizations to be taken directly to the community (with the aid of a laptop computer and a projector device) or be shared online, at a low cost and with wide accessibility, increasing the reach of societal participation (Hudson-Smith et al., 2005).

Finally, the team had to plan strategies of evaluation regarding the visualizations' impacts. Because the participants varied in each workshop and presentation, and the number of participants was often large, it was deemed unfeasible to individually track reactions within the short available timeframe, and instead general reports by the FDC members of each instance of interaction were chosen as the main source of information.

\section{VISUALIZATION PROOF OF CONCEPT - PONTA NEGRA BEACH}

The FDC noted the discussions on the densification of coastal areas as one of the main points of contention during the revision process. Current law determines severe restrictions to building height along the coastal areas of Natal as a means of preserving public fruition of the natural landscape, including important landmarks such as the "Morro do Careca" sand dune in the "Ponta Negra" beach area. This area was chosen as the first target for a proofof-concept visualization, intent on testing the parametric modeling process and creating visualizations that could demonstrate the effects of changing two building parameters: maximum floor-to-area ratio (FAR) and maximum building height.

The modeling process involved creating a topographical surface and extruding building projections based on CAD information, up to the current height (which had to be approximate, as no comprehensive information was available. This resulted in a total 6914 extrusions, some of which (situated in 61 city blocks near the coastline) were moved to a hidden model layer and replaced by parametrically generated geometries. These were created using the DecodingSpaces plugin for Grasshopper, which is capable of procedurally generating plot limits based on block outlines and a plot width threshold parameter, as well as the building extrusion itself, by calculating a target maximum number of floors based on an FAR parameter.

The visualizations represented the current situation, as well as scenarios FAR settings of 1.2, 2.0 and 3.5, while abolishing maximum height limits (Figure 2). These were never meant to represent actual proposals, but as an example capable of demonstrating the effects on urban morphology brought about by changing these parameters. The resulting visualizations clearly display potential for landscape occlusion and building shadow projection over the beach area in these hypothetical scenarios. 

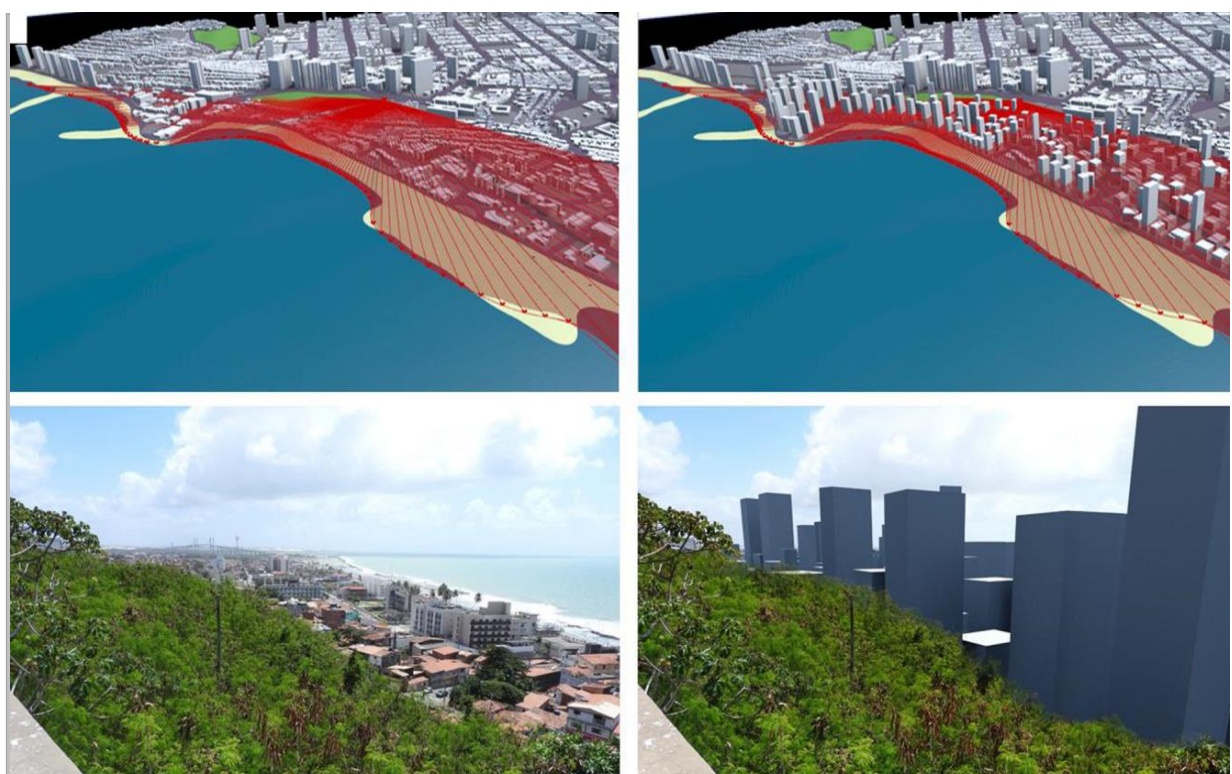

Figure 3: "Praia do Meio" visualizations: Bird's eye view, current (top-left); Bird's eye view, FAR 3.5 (top-right); Street-level, current (bottom-left); Street-level, FAR 3.5 (bottom-right). The building height cut-off plane is represented in red in the top images.

\section{VISUALIZATION BY REQUEST - PRAIA DO MEIO BEACH}

Having presented these visualizations in an open workshop in which the FDC discussed the city's coastal spaces, the team was called upon to address an area undergoing strong pressure by the building industry. The inhabitants of the "Brasilia Teimosa" community in the "Praia do Meio" area, characterized by low average income (as recognized by the current Director Plan) and work activities directly related to the coastal environment, were concerned that regulation changes in the social interest special zone might force them to leave their traditional homes.

This is an area of greater complexity, both in its social and spatial, as well as in planning parameters, as it comprises a special touristic interest zone (which limits building height based on a line-of-sight cone, from a lookout point down to the coast) as well as a social interest special area (which disallows parcel reconfiguration in order to curb building industry pressures and preserve the traditional communities' right to reside in that area).

The line-of-sight cone was parametrically modeled in Grasshopper based on the lookout point and the coastal line, as a dynamic cut-off plane for building height. Several scenarios were developed using the methods previously explored in Ponta Negra, representing the current situation; a densification scenario using higher FAR and maintaining the height cut-off plane; and additional situations in which none of the special areas were considered. These images were presented as bird-eye views as well as street-level views, situated on the lookout point and with the parametrically generated buildings digitally composed over a photograph taken that that spot. Once again, the visualizations were able to show the occlusion of the natural landscape by buildings, if the current limits were to be removed. (Figure 3 )
Beyond the modeling of building morphology, a new definition was created to calculate the potential resident population in each scenario, based on parameters for minimum residential unit area and inhabitants per residence. These results allowed us to compare current populational density (110 people per hectare) with the projected population for each scenario: 340 p/ha by fully utilizing the building potential under current law; or up to $800 \mathrm{p} / \mathrm{ha}$ if current restrictions were lifted, and the FAR raised to 3.5. Given that this area's sanitation infrastructure is predicted to serve up to a density of 144 p/ha by the year 2024, the modeling efforts were able to demonstrate that, beyond the impacts on landscape and social use, an increase in density would severely overload the existing infrastructures, likely resulting in the pollution of local beach water and ground.

\section{PRESENTING THE VISUALIZATIONS}

The visualizations for the Ponta Negra and Praia do Meio scenarios were presented directly to the public in the Brasília Teimosa community as part of expositions aimed to instruct the citizens in several aspects of the Director Plan, including density zoning, special zones and floor-toarea ratio calculations. Oral surveys conducted before and after these presentations indicated a vast majority of the participants lacked understanding of these concepts prior to the meetings, and had acquired a baseline understanding afterwards. The recognition of their own area and familiar landmarks was especially commented on during the discussions. This did not, however, seem to reflect in an increase in citizen participation in the official workshops - the tight schedule and the fact that these took place mostly during work hours in weekdays continued to suppress citizen presence.

When presented during these official workshops, over the August/September 2019 phase of the revision debates, the 
visualizations elicited a wide range of reactions. Despite being shown in a fully transparent manner, with explanations of each step, they were deemed "irresponsible" and even "terrorist" by building industry advocates - which were proposing increases of FAR parameters (which currently range from 1.2 to 3.5 ) to levels up to 7.0 , and were displeased with the presentation of the full visual impact of high FAR construction. The calculations of impact on sanitation infrastructure would also become a central point in the discussions.

After these workshops, and despite the team's best efforts to keep the visualizations attached to the respective methodology and parameter explanations, some of the images began circulating out of context through socia media. The sharing of extreme case scenarios, coupled with a lack of proper information, increased the reach of the visualizations, but did not contribute to a qualified understanding of the underlying concepts. In order to combat misinformation, the FDC team developed purposemade videos aiming to instruct on the specific issues the visualizations were meant to address and continued to present the visualizations directly to interested parties.

During the following months, thematic workgroups formulated proposals based on the planning discussions. At this point, the highest FAR proposals were no longer present, and the main density control was based on calculating FAR based on available sanitation infrastructure - which may have been a result of the FDC's efforts (including the visualizations) to demonstrate the inadequacy of the current infrastructure to the extreme densification intended by the building industry advocates.

\section{THE VISUALIZATIONS IN THE CONTEXT OF THE COVID-19 PANDEMIC}

Having considered the need for additional clarity and an increase in human resources dedicated to producing the visualizations, the FDC team organized a workshop aimed at training planning students and professionals in the use of parametric urban modeling tools and techniques. This was planned to be a two-part event, scheduled to take place on March 16 and March 23, 2020.

The first workshop day was attended by 24 participants, and included an introduction to parametric modeling and the use of the Grasshopper software; as well as the presentation of the methods used by the modeling team to achieve the visualization results, including the modeling and density calculation algorithms.

The second day was scheduled to include a case study presentation, a site visit, and the development of visualization scenarios covering a large urban area, comprising the surroundings of the João Medeiros Filho avenue and the neighboring urban and mangrove areas, which are currently a prime target for the building industry, despite the proximity to fragile natural environments and water sources (Figure 4). The 24 participants were to organize into groups and each present a different scenario with varying areas of effect and building parameters. The results would then be discussed and evaluated in a workshop "debriefing" stage, in order to exchange ideas, foster reflection and help coalesce the acquired experience into knowledge (Crookall, 2010).

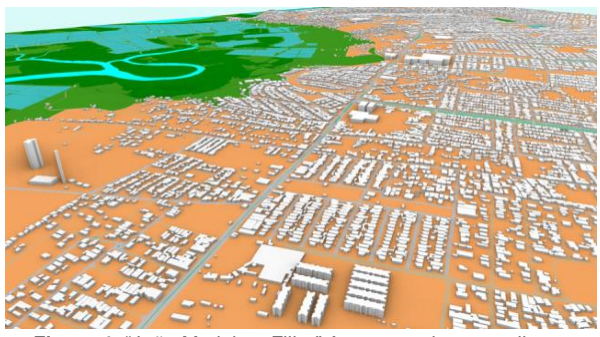

Figure 4: "João Medeiros Filho" Avenue and surrounding areas.

A day after successfully completing the first step on March 16th, all academic activities were halted due to the determination of social isolation in response to the SARSCoV2/COVID-19 pandemic. The plan revision process was likewise halted.

During the March to June 2020 period, given the uncertainty of the upcoming schedule, the visualization team dedicated its efforts to producing illustrations for online distribution, explaining concepts in the Director Plan. As the revision process was resumed in July 2020 despite the impossibility of physical contact, the FDC's efforts were once again intensified. The visualization team finalized the model meant to be developed in the March workshop, covering over $31 \mathrm{~km}^{2}$ and 50.000 extrusions - which proved to be near the maximum working limit for the available hardware/software configuration, and required a downgrade in topography detail.

Also during the month of July 2020, an external group engaged in the revision process used the Ponta Negra visualization (specifically, the most extreme densification scenario, taken out of context, without permission from the visualization team and without the required information) in their own campaign denouncing the risks associated with changes to the Director Plan - an online petition illustrated by that visualization has reached over 21.000 signatures. As of October 2020, the revision process has once again been suspended due to irregularities in the registration of delegates who were expected to vote on planning law changes.

\section{EVALUATING THE PROCESS (THUS FAR)}

The parametric models have proven to be a viable way to produce visualizations in a short timeframe: three days for the Ponta Negra model; one week for the Praia do Meio model, including the development of specific algorithms; and one week for the João Medeiros Filho model, including a large urban area. Furthermore, these were modeled using limited resources: one desktop computer with the Rhinoceros software, and another with the AutoCAD software; CAD-only maps and sparse demographic/ infrastructure data; and a small modeling team.

As the revision process continues under intense dispute and accusations of the municipality's administration ignoring and/or suppressing citizen participation amidst an unprecedented public health hazard situation, the visualizations remain a focal point of the discourse. By including local landmarks - such as the Morro do Careca dune in Ponta Negra, the Reis Magos Fortress and the Newton Navarro Bridge in the vicinity of Praia do Meio, and 
the mangrove preservation zone in the João Medeiros Filho area - the visualizations become instantly recognizable, despite the low level of realism instilled into the model. The use of photographic compositing in the Praia do Meio street-level visualizations do not appear to have elicited substantially different reactions to the purely computergenerated models used in the Ponta Negra scenarios, and evaluating its impact would require further experimental studies under more controllable circumstances.

Structured presentations using the visualizations have been well-received by non-expert audiences attempting to gain an understanding of planning concepts, especially when depicting the context said audience is in, their homes and surroundings. The amount of presentations and interactions that can be performed in person by the team is limited, however, and the images have instead attained a wider reach through social media sharing, outside the visualization team's control. In such cases, the visualizations are often presented in a sensationalistic fashion, and are unaccompanied by the necessary explanations, which undermines its objectives of exploration, explanation, and education, even if they're being used as a means of increasing engagement through "shock value".

Despite this undesired exposition, there have been noticeable responses to the concerns presented by the FDC and illustrated by the visualizations: sanitation infrastructure has taken on a central role in the current proposals for limiting FAR allowances, and the most extreme FAR proposals have apparently been sidelined; the local planning agency has created their own visualization studies for their proposals for Ponta Negra beach, in which they commit to preserving the landscape viewing properties; there have been no further proposals threatening the social interest area in Praia do Meio.

While the FDC's efforts and the visualizations may have contributed to some gains in preserving the citizens' right to the city, the ongoing situation remains concerning, as the process advances using exclusively online tools - despite a lack of online access by much of the city's low income population.

Likewise, the visualization team's plans to extend the reach of the techniques to other planning professionals and demonstrate the transparency of the methods have been postponed due to the social isolation requirements. A new version of the workshop in 2021, either in online form although steep computer hardware requirements will restrict the amount of participants which will have access to the event, and no site visits will be possible, or in standard lab format, once the social distancing restrictions have been lifted.

As electronic tools appear to be a solution for many limitations imposed by the COVID-19 pandemic, and even as the modeling team makes use of digital graphics and parametric modeling to help communicate and engage citizens in participatory planning, there remains a concern as to how the inequality in access to such tools might present obstacles to participation of communities that can be deeply affected by changes in urban plans.
The visualization efforts have been a disruptive element in a process that, despite being superficially participatory, has often been conducted in a rushed manner, with little regard to data openness and discussion. While the effects these activities might ultimately have on the revised urban plan is unclear, there has been a surge in interest in parametric urban modeling techniques amongst planning students and professionals, as well as increased calls for data and modeling transparency in the definition of urban parameters.

\section{REFERENCES}

Al-Kodmany, K. (1999). Using visualization techniques for enhancing public participation in planning and design: Process, implementation, and evaluation. Landscape and Urban Planning, 45(1), 37-45.

Al-Kodmany, K. (2002). Visualization tools and methods in community planning: From freehand sketches to virtual reality. Journal of Planning Literature, 17(2), 189-211.

Batty, M., Steadman, P., \& Xie, Y. (2004). Visualization in Spatial Modeling. UCL Working Papers Series, 79, 1-28.

Brasil (2001). Lei N. 10.257, de 10 de Julho de 2001.

Crookall, D (2010). Serious games, Debriefing, and Simulation/Gaming as a Discipline. Simulation \& Gaming. 41 (6), 898-920.

De Castro, M. M., Nogueira, R. H., De Aguiar, T., Moura, A. C. M., \& De Oliveira, F. H. (2018). Parametric modeling as an alternative tool for planning and management of the Urban Landscape in Brazil - Case study of Balneario Camboriu. DISEGNARECON, 11(20), 17.1-17.13.

Hoch, C., Zellner, M., Milz, D., Radinsky, J., \& Lyons, L. (2015). Seeing is not believing: cognitive bias and modelling in collaborative planning. Planning Theory and Practice, 16(3), 319-335.

Hudson-Smith, A., Evans, S., \& Batty, M. (2005). Building the virtual city: Public participation through e-democracy. Knowledge, Technology \& Policy, 18(1), 62-85.

Kallus, R. (2016). Citizenship in action: participatory urban visualization in contested urban space. Journal of Urban Design, 21(5), 616-637

Lange, E. (2001). The limits of realism: Perceptions of virtual landscapes. Landscape and Urban Planning, 54(1-4), 163182.

Lovett, A., Appleton, K., Warren-Kretzschmar, B., \& Von Haaren, C. (2015). Using 3D visualization methods in landscape planning: An evaluation of options and practical issues. Landscape and Urban Planning, 142, 85-94.

Natal, Prefeitura Municipal (2007). Lei Complementar n 082.

Pettit, C. J., \& Industries, P. (2006). A participatory planning support tool for imagining landscape futures. 2(3), 1-17.

Radinsky, J., Milz, D., Zellner, M., Pudlock, K., Witek, C., Hoch, C. \& Lyons, L. (2017). How planners and stakeholders learn with visualization tools: using learning sciences methods to examine planning processes. Journal of Environmental Planning and Management, 60(7), 1296-1323.

Remaking Cities Institute. (2019). 3D / Data Visualization for Urban Design and Planning.

Sheppard, S. R. J. (2001). Guidance for crystal ball gazers: Developing a code of ethics for landscape visualization. Landscape and Urban Planning, 54(1-4), 183-199. https://doi.org/10.1016/S0169-2046(01)00135-9 